\title{
Antistreptokinase antibodies: implications for thrombolysis in a region with endemic streptococcal infection
}

\author{
N Blackwell, A Hollins, G Gilmore, R Norton
}

J Clin Pathol 2005;58:1005-1007. doi: 10.1136/icp.2004.025312

Aims: To determine antistreptokinase antibody (anti-SK) titres in patients with the acute coronary syndrome from communities with endemic group A streptococcal infection because of the implications for streptokinase (SK) thrombolysis.

Methods: Anti-SK titres were determined using a standard method in 47 consecutive SK naive patients, presenting to the Mt Isa Hospital emergency department, Australia, with an acute coronary syndrome. Both indigenous and nonindigenous subjects were enrolled. Antistreptolysin $O$ (ASOT) and anti-DNAse B (ADB) titres were also determined. Results: Indigenous patients were more likely to have anti-SK antibodies $(p<0.001)$ than the non-indigenous cohort. Anti-SK antibody titres also correlated well with ASOT/ADB titres.

Conclusions: Anti-SK antibodies are highly prevalent in SK naive indigenous patients presenting with the acute coronary syndrome. Streptokinase should not be used for thrombolysis in populations with endemic group A streptococcal infection.

$\mathrm{T}$ he risk adjusted mortality rate from ischaemic heart disease (IHD) in Australian indigenous patients is 1.9 times the Queensland average and is the largest single contributor to excess mortality in the indigenous population. In the under 54 years old age group, the mortality rate from IHD is seven to 12 times higher than in the non-indigenous population. ${ }^{1}$ Streptokinase (SK) is still widely used in the treatment of acute myocardial infarction. Group A streptococcal infections are highly prevalent in indigenous patients in this region. A study from Darwin, Australia ${ }^{2}$ has shown high titres of antistreptokinase (anti-SK) IgG and has suggested the existence of SK resistance in a Northern Territory Aboriginal population; these were not patients with probable IHD. A retrospective local (unpublished) chart review (1 April 1999 to 31 May 2000) showed that SK induced thrombolysis failed in $66 \%$ of indigenous patients (based on Duke Q wave electrocardiogram criteria) compared with $41 \%$ of non-indigenous patients.

"The risk adjusted mortality rate from ischaemic heart disease in Australian indigenous patients is 1.9 times the Queensland average and is the largest single contributor to excess mortality in the indigenous population"

Therefore, we conducted a cross sectional study, comparing indigenous patients presenting with chest pain with nonindigenous controls. Serological evidence of previous streptococcal exposure and the presence of anti-SK antibodies were sought to determine the suitability of SK as a thrombolytic agent in these populations.

\section{METHODS}

Extensive consultation was undertaken with local indigenous groups to discuss our study. In particular, how the goals of our study might be achieved in the interests of helping address the heavy burden of IHD on the local indigenous community. Local hospital ethics committee approval was obtained.

\section{Patients}

All SK naive patients presenting to the emergency department of the Mt Isa Hospital, Australia with chest pain suggestive of an acute coronary syndrome were considered for inclusion. In total, 47 patients were recruited over a six month period, $19(40.4 \%)$ of whom were indigenous. Indigenous people make up about $20 \%$ of the population of the health district, thus they were over-represented in our sample. Two patients declined entry into the study, giving a total of 49 possible participants. Blood was taken for anti-SK antibody determination before treatment was administered. Written informed consent was also obtained.

\section{Antistreptolysin $O$ and anti-DNAse B antibody determination}

The detection of antistreptolysin O (ASOT) and anti-DNAse B (ADB) antibodies was performed using standard methods (bioMerieux, Baulkham Hills, New South Wales, Australia). Positive ASOT and ADB were defined as titres > 200 .

\section{Anti-SK antibody assay}

An in house modification of the method of Urdahl and colleagues $^{2}$ was used. Microtitre plates were coated with SK in buffer, incubated, washed, and blocked with bovine serum albumin. Diluted patient serum samples were incubated in the wells, washed, and incubated with horseradish peroxidase conjugated IgG. Substrate was added and the optical density (OD) read at 450 and $620 \mathrm{~nm}$ on an LP400 plate reader (Diagnostics Pasteur, North Ryde, Australia).

Optimal SK antigen and serum concentration titrations were determined. These were $60 \mathrm{IU} /$ well of SK with a serum dilution of 1/30 000. Each run of 16 wells included a blank, a duplicate well for each sample, and one each of a negative, a low, and a high anti-SK sample. ASOT and ADB negative sera were used to validate the anti-SK assay. The cutoff value for the anti-SK assay was calculated from the mean optical density readings of the ASOT/ADB negative sera (mean OD reading $+2 \mathrm{SD}$ ).

\section{RESULTS}

From a total of 47 patients, 19 indigenous patients and 28 non-indigenous controls were recruited. There were 36 men and 13 women. Ages ranged between 26 and 88 years. The

Abbreviations: $A D B$, anti-DNAse $B$ antibodies; $A S O T$, antistreptolysin O antibodies; IHD, ischaemic heart disease; OD, optical density; SK, streptokinase 
Table 1 Summary of anti-SK results and ASOT/ADB titres in the study group $(n=47)$

\begin{tabular}{lllll}
\hline & Indigenous & Non-indigenous & Total & p Value \\
\hline Positive ASOT/ADB titres & $14 / 19(74 \%)$ & $4 / 28(14 \%)$ & $18 / 47(38 \%)$ & $<0.001$ \\
Positive anti-SK & $14 / 19(74 \%)$ & $7 / 28(25 \%)$ & $21 / 47(45 \%)$ & $<0.001$ \\
Equivocal anti-SK & $3 / 19(16 \%)$ & $4 / 28(14 \%)$ & $7 / 47(15 \%)$ & $\mathrm{NS}$ \\
Negative anti-SK & $2 / 19(10 \%)$ & $17 / 28(61 \%)$ & $19 / 47(40 \%)$ & $<0.001$ \\
\hline ADB, anti-DNAse B antibodies; ASOT, antistreptolysin O antibodies; NS, not significant; SK, streptokinase.
\end{tabular}

mean age was 48 (SD, 11.8) and 58 years (SD, 13.0) in indigenous and non-indigenous patients, respectively. Indigenous patients were significantly younger $(\mathrm{p}<0.05)$. The cutoff OD reading for a positive anti-SK assay was determined to be greater than 0.42 . (mean $+2 \mathrm{SD}$ ). The result was deemed equivocal if the OD reading was between 0.18 (mean negative OD of negative ASOT and ADB sera) and 0.42 . A negative result was an OD below 0.18 . Table 1 shows a summary of our results.

Almost three quarters (14 of 19) of the indigenous patients in the study had positive anti-SK antibodies, with another three showing equivocal antibody values, which was highly significant in comparison with non-indigenous controls $\left(\chi^{2}\right.$ test). A similarly high proportion of indigenous patients showed evidence of previous group A streptococcal infection, as indicated by positive ASOT and ADB titres. The correlation between anti-SK antibody values and ASOT/ADB titres was strong, with a $75 \%$ positive predictive value and a $95 \%$ negative predictive value in this population.

\section{DISCUSSION}

A previous study has shown that indigenous people in the Northern Territory of Australia have the highest incidence of rheumatic fever in the world. ${ }^{3}$ Our present study highlights another manifestation of the protean consequences of group A streptococcus interacting with the human immune system.

Research in Aboriginal communities is challenging. ${ }^{4}$ Staff struggle to address basic health needs. Most remote communities are small, limiting sample sizes, yet these are where the needs may be greatest. Access is time consuming and expensive, cultural issues are significant, staff turnover is high, and English is usually a second or third language in the community. Resources and infrastructure mitigate against conducting well designed clinical research, and indigenous patients are thus under-represented in the health literature. The relative paucity of studies considering the health needs of indigenous Australians reflects the operation of the inverse care law. The results of this study will consequently be presented to and discussed with local indigenous groups who were involved in the planning stages.

\footnotetext{
"Resources and infrastructure mitigate against conducting well designed clinical research, and indigenous patients are thus under-represented in the health literature"
}

Several researchers from other countries have examined the relation between anti-SK antibody titres and the efficacy of SK in acute myocardial infarction. One study showed that high anti-SK antibody titres inhibited the action of SK. Another study ${ }^{6}$ showed that after SK thrombolysis, those patients without evidence of coronary reperfusion on dynamic vector cardiography had significantly higher antiSK antibodies. An angiographic study ${ }^{7}$ showed that patients with persisting coronary occlusion at 24 hours tended to have higher anti-SK antibody titres. Buchalter et al showed that exposure to SK within the previous two years was a contraindication to further SK administration because of persisting anti-SK antibodies. ${ }^{8}$ The population in that study had non-significant levels of anti-SK antibodies before SK thrombolysis.

An unexpected finding of our study was the significant proportion of non-indigenous patients with positive anti-SK titres. This contrasts with a study from Birmingham, UK, which found low titres of anti-SK antibodies in both the general population and patients with myocardial infarction. This would reflect the overall high background rate of group A streptococcal infection in the geographical region examined in our study. In India, titres of anti-SK antibody were such that at least twice the conventional dose of SK would have been needed to neutralise its effect. ${ }^{10}$ However, another study from India ${ }^{11}$ showed no relation between pretreatment antiSK antibody titres and reperfusion rates, although basal antibody values were relatively high in all patients, suggesting a potential compromise of the action of SK across the entire study population.

We have shown that there is a significantly higher prevalence of anti-SK antibody in indigenous patients with probable IHD in North West Queensland compared with nonindigenous longterm residents ( $74 \% v 25 \%$; p $<0.001)$. These indigenous patients were concentrated in the $<54$ age group, where SK antibody titres were highest, and where as mentioned earlier mortality is seven to 12 times that of non-indigenous age matched controls. This suggests that SK should not be used for thrombolysis in such indigenous patients. Similarly, patients who have been exposed to SK in the previous two years would have SK antibodies that would be expected to neutralise the standard dose of SK.

Our study could be criticised because definitive (angiographic) evidence of IHD was not obtained. Unfortunately, because of the non-availability of services, many patients living in remote areas do not undergo angiography, either acutely or electively, in the investigation of presumed acute coronary syndrome. Entry into the study was deliberately based around symptoms suggesting an acute coronary

\section{Take home messages}

- In North West Queensland, anti-streptokinase (SK) antibodies are highly prevalent in SK naive indigenous patients presenting with the acute coronary syndrome

- Indigenous patients were more likely to have anti-SK antibodies ( $75 \%$ prevalence) than non-indigenous patients, although the prevalence of anti-SK antibodies was also quite high (25\%) in the non-indigenous cohort

- Routine assessment of anti-SK antibodies is not generally available, but anti-DNAse B and antistreptolysin $O$ antibody titres are reliable and readily assayed surrogates

- Streptokinase should not be used as first line agent for thrombolysis in populations with endemic group $A$ streptococcal infection, although doubling the dose may be an alternative if more expensive thrombolytic agents are not available 
syndrome, rather than a definitive diagnosis. Electrocardiographic based studies of successful reperfusion are controversial, and there is no wide agreement on validated criteria between authorities. Because of the low population density in this region, it was felt that a symptom based entry criterion was appropriate, and it is unlikely that more compelling evidence will be obtained about the use of SK in indigenous patients.

Routine assessment of anti-SK antibodies is not generally available, although as this study shows, ASOT and ADB titres are reliable and readily assayed surrogates.

Although more expensive thrombolytic agents would probably be more effective, these drugs are not available in rural and remote settings, and double dosing with SK should be considered in an effort to neutralise high antibody titres. ${ }^{12}$

The chances of a rural patient achieving successful thrombolysis should not be compromised by relying on SK, which although relatively cheap is less likely to be effective. SK should be regarded as an inappropriate first line agent for thrombolysis across the top end of Australia, because lysis would be expected to fail in $75 \%$ of indigenous patients and $25 \%$ of non-indigenous patients.

\section{ACKNOWLEDGEMENTS}

This study was supported by a research grant from the Mt Isa Centre for Rural and Remote Health.

\section{Authors' affiliations \\ N Blackwell, A Hollins, Mount Isa Hospital, Mount Isa, Queensland 4825, Australia \\ G Gilmore, R Norton, Clinical Microbiology, QHPS, The Townsville Hospital, Townsville, Queensland 4814, Australia}

Correspondence to: Dr R Norton, Clinical Microbiology, The Townsville Hospital, Townsville, Queensland 4814, Australia; Robert_Norton@ health.qld.gov.au

Accepted for publication 15 February 2005

\section{REFERENCES}

1 Australian Institute of Health and Welfare. Aboriginal and Torres Strait Islander people. In: Australia's Health 2004. Canberra, Australia: Australian Institute of Health and Welfare, 2004:211-17.

2 Urdahl KB, Matthews JD, Currie BJ. Anti-streptokinase antibodies and streptokinase resistance in an Aboriginal population in Northern Australia. Aust NZ J Med 1996;26:49-53.

3 Carapetis JR, Wolf DR, Currie BJ. Acute rheumatic fever and rheumatic heart disease in the top end of Australia's Northern Territory. Med J Aust 1996; 164:146-9.

4 Morris PS. Randomised controlled trials addressing Australian Aboriginal health needs: a systematic review of the literature. J Paediatr Child Health 1999:35:130-5.

5 Lynch M, Pentecost BL, Littler WA, et al. The significance of antistreptokinase antibodies. Clin Exp Immunol 1994;96:427-31.

6 Juhlin P, Bostrom P-A, Torp A, et al. Streptokinase antibodies inhibit reperfusion during thrombolytic therapy with streptokinase in acute myocardial infarction. J Int Med 1999;245:483-8.

7 Gemill JD, Hogg KD, Dunn FG, et al. Pre-dosing antibody levels and efficacy of thrombolytic drugs containing streptokinase. Br Heart J 1994;72:222-5.

8 Buchalter MB, Suntharalingham G, Jennings I, et al. Streptokinase resistance: when might streptokinase administration be ineffective? $\mathrm{Br}$ Heart $J$ 1992;68:449-53.

9 Lynch M, Pentecost BL, Littler WA, et al. The distribution of antibodies to streptokinase. Postgrad Med J 1996;72:290-2.

10 Alexander T, Krishnaswami S, Khanduri U. Anti-streptokinase levels in Indian patients. Int J Cardiol 1991;32:361-4.

11 Shaila G, Chandrashekar YS, Kumar N, et al. Antistreptokinase antibodies before and after streptokinase therapy in patients with acute myocardial infarction from areas endemic with streptococcal infection and influence on reperfusion rates. Am J Cardiol 1994;74:187-9.

12 Anderson HR, Nielsen T, Rasmussen K, et al. A comparison of coronary angioplasty with fibrinolysis in the treatment of myocardial infarction. N Engl J Med 2003;349:733-42. 